\title{
Anti-Helicobacter pylori seropositivity: Influence on Severity and Treatment Response in Patients with Chronic Hepatitis C
}

\author{
Takeji Umemura, ${ }^{1, a}$ Hidetomo Muto, ${ }^{1, a}$ Eiji Tanaka, ${ }^{1}$ Akihiro Matsumoto, ${ }^{1}$ \\ Tetsuya Ichijo, ${ }^{1}$ Kaname Yoshizawa, ${ }^{1}$ Taiji Akamatsu, ${ }^{2}$ Kendo Kiyosawa ${ }^{1}$ \\ and the Nagano Interferon Treatment Research Group
}

1: Department of Internal Medicine, Gastroenterology and Hepatology, Shinshu University School of Medicine, Matsumoto, Japan

2: Department of Endoscopy, Shinshu University School of Medicine, Matsumoto, Japan

Short title: H.pylori and chronic hepatitis C

Financial support:

The present study was supported in part by a Grant-in-Aid from the Ministry of Health, Labour and Welfare of Japan.

a Both authors contributed equally to this study.

Corresponding author: Takeji Umemura, MD, PhD. Department of Medicine, Shinshu University School of Medicine, 3-1-1 Asahi, Matsumoto, 390-8621, Japan. Tel:81-263-37-2634, Fax:81-263-32-9412, E-mail: t-ume@hsp.md.shinshu-u.ac.jp 


\section{Summary}

We sought to clarify the incidence and role of Helicobacter pylori (H.pylori) seropositivity in patients with hepatitis $\mathrm{C}$ virus $(\mathrm{HCV})$ infection and the effect of coinfection on interferon- $\alpha$ and ribavirin therapy. The presence of H.pylori was tested using a commercially available enzyme immunoassay in serum samples from 93 patients with chronic hepatitis C. Clinical features, HCV markers, and response of HCV to interferon- $\alpha$ and ribavirin were compared between H.pylori-positive and H.pylori-negative patients. Anti-H.pylori antibody was detected in 45 (48\%) of the 93 patients, whose median HCV RNA level (495 vs. $760 \mathrm{KIU} / \mathrm{ml} ; P=0.013$ ) and platelet count (128 vs. $\left.158 \times 10^{3} / \mu \mathrm{l} ; P=0.009\right)$ were significantly lower than in patients with HCV infection alone. Anti-H.pylori levels were found to be significantly correlated with fibrosis score $(P=0.0083, r=0.33)$ but inversely related to platelet count $(P=0.0037$, $r=-0.34)$. The sustained response rate for HCV clearance following interferon- $\alpha$ and ribavirin treatment did not differ between patients with and without anti-H.pylori seropositivity. The presence of H.pylori (odds ratio, 8.61: 95\% confidence interval 1.59-46.70) and fibrosis score (odds ratio 30.13: 95\% confidence interval 5.44-166.78) were found by multivariate analysis to be associated with the decrease of platelet count during therapy. Coexistent H.pylori infection does not demonstrably influence the clinical course of chronic hepatitis C. A possible connection between H.pylori coinfection and thrombocytopenia was found during treatment course, suggesting that pre-emptive eradication of H.pylori may facilitate completion of treatment and increased sustained virological response.

Keywords: Hepatitis C virus, interferon, ribavirin, Helicobacter pylori, thrombocytopenia.

Word count abstract: 236 


\section{INTRODUCTION}

Hepatitis $\mathrm{C}$ virus (HCV) is a major cause of posttransfusion hepatitis and chronic liver disease [1, 2]. More than half of patients with acute HCV infections develop chronic hepatitis that leads to liver cirrhosis and/or hepatocellular carcinoma in at least $20 \%$ of cases [3, 4]. Treatment of HCV with interferon (IFN)- $\alpha$ and ribavirin is associated with a sustained response rate of nearly $40 \%[5,6]$, which is likely to improve to $55 \%$ of treated patients with the use of pegylated IFN- $\alpha$ and ribavirin in [7, 8].

Helicobacter pylori (H.pylori) is a gram-negative bacillus that colonizes the mucous layer of the human stomach. This bacterium has been causally linked with a diverse spectrum of gastrointestinal disorders, including gastritis, peptic ulcer disease, gastric adenocarcinoma, and mucosa-associated lymphoid tissue (MALT) lymphoma. Several studies have reported association of H.pylori infection to a variety of liver diseases, such as hepatitis A virus, primary biliary cirrhosis, and autoimmune hepatitis [9-17]. Patients with chronic liver diseases have also been reported to be significantly more likely to be infected with H.pylori than controls. Pellicano et al. reported that approximately $90 \%$ of 254 patients with HCV-related cirrhosis in Italy were seropositive for anti-H.pylori antibodies [11]. However, there is no current evidence as to whether H.pylori worsens the course of coexistent hepatitis C. In addition, the effect of H.pylori on HCV response to IFN- $\alpha$ and ribavirin is largely unknown.

The objective of this study was to determine the prevalence of anti-H.pylori seropositivity in Japanese patients with chronic hepatitis $C$, the influence of anti- $H$. pylori seropositivity on the clinical, virological, and histological characteristics of hepatitis $\mathrm{C}$, and the effect of H.pylori coinfection on HCV response to IFN- $\alpha$ and ribavirin therapy. 


\section{PATIENTS AND METHODS}

\section{Patients}

A total of 93 patients with chronic hepatitis C (47 men and 46 women; mean age 58 years [range: 25-74]) who were seen at Shinshu University Hospital and affiliated hospitals of the Nagano Interferon Treatment Research Group between December 2001 and January 2003 were enrolled in the present study. All patients were positive for antibody to HCV (anti-HCV) and positive for HCV RNA. Diagnosis of chronic hepatitis $\mathrm{C}$ was based on the following criteria: 1) persistent elevation of serum alanine aminotransferase (ALT) levels for at least 6 months; 2 ) absence of detectable hepatitis B surface antigen; and 3) exclusion of other causes of chronic liver diseases, such as alcoholic liver injury, autoimmune hepatitis, primary biliary cirrhosis, hemochromatosis, and Wilson disease. No patients had a history of decompensated cirrhosis or hepatocellular carcinoma, and all were negative for antibody to the human immunodeficiency virus. Of the 93 patients, 62 had had a liver biopsy prior to IFN and ribavirin combination therapy. Seven of the 93 patients were diagnosed as having cirrhosis. Written informed consent was obtained from each patient.

\section{IFN and ribavirin combination therapy}

IFN- $\alpha 2 b$ (Schering-Plough, Tokyo, Japan) was administered at a dosage of 6 million units (MU) daily for 2 weeks, followed by $6 \mathrm{MU}$ three times a week for 22 weeks (total dose, 480 million $U$ ). Rivabirin was taken daily for 24 weeks (body weight $<60 \mathrm{~kg}, 600$ $\mathrm{mg} /$ day; $\geq 60 \mathrm{~kg}, 800 \mathrm{mg} / \mathrm{day})$. Patients were followed for at least 6 months after therapy. For all patients, serum samples were obtained prior to therapy and stored at $-70^{\circ} \mathrm{C}$ until testing. Additional serum samples were collected just before therapy began, during therapy, immediately after therapy was completed, and 6 months post-therapy.

Serum ALT levels were measured prior to therapy and, in patients receiving IFN- $\alpha$ and ribavirin therapy, at least once every 4 weeks both during therapy and follow-up. Sustained virological responders (SVRs) to IFN and rivabirin therapy were defined as those whose HCV RNA in serum was undetectable 24 weeks after completing therapy. Non-responders and relapsers who did not meet SVR criteria were defined as non-SVRs.

Necroinflammatory activity was scored according to the histology activity index (HAI) by Knodell et al [18]. The HAl score was determined by combining the scores for portal inflammation (0-4), lobular degeneration and necrosis (0-4), and periportal 
necrosis (0-10). Fibrosis stage was defined according to the Scheuer fibrosis score: 0 , absence; 1 , fibrous portal expansion; 2 , periportal or portoportal fibrosis; 3 , bridging fibrosis; 4, cirrhosis [19]. Investigators involved in this part of the study were blinded to the results of other portions.

Safety was assessed in this study by recording adverse events reported by patients, clinical laboratory test results (including hematology, blood chemistry, and urinalysis), and vital signs.

\section{Serological markers and molecular assays for HCV, HBV, HIV and H. pylori}

Anti-HCV antibody, hepatitis B surface antigen and antibody to human immunodeficiency virus were measured using commercially available enzyme-linked immunosorbent assays (International Reagents Co., Kobe, Japan). IgG class antibody to H.pylori (anti-H.pylori) was also detected using an enzyme immunoassay kit (Kyowa Medex Co., Tokyo, Japan). This particular assay has been shown to be an accurate and reliable method for detection of $H$. pylori infection, and is based on high-molecular-weight cell-associated antigens which are highly conserved complexes with important conformational determinants. The enzyme immunoassay kit cutoffs used were those recommended by the manufacturer and were as follows: positive, >2.2 enzyme immunoassay value (EV); indeterminate, 1.8-2.2 EV; and negative, <1.8 EV [20]. In this study, patients positive for anti-H.pylori were defined as $>2.2 \mathrm{EV}$ in serum. Patients who did not meet these criteria, including negative and indeterminate, were regarded as negative for anti-H.pylori. The sensitivity and specificity of this assay were $94.0 \%$ and $82.4 \%$, respectively. Serum levels of HCV RNA were determined using qualitative and quantitative COBAS AMPLICOR assays (Nippon Roche Co. Ltd, Tokyo, Japan), which amplify HCV RNA by reverse-transcription-polymerase chain reaction [21]. HCV genotypes were determined by INNO-LiPA HCV II (Innogenetics, Gent, Belgium). ALT, and other relevant biochemical tests, were performed using standard methods.

\section{Statistical analysis}

Mann-Whitney $U$ test was used to analyze continuous variables. Chi-square test with Yates' correction was used for the analysis of categorical data. Pearson's correlation coefficient was used to evaluate the relationships between the titer of anti-H.pylori and platelet count or fibrosis score. Multivariate analysis was performed using a logistic regression model with a stepwise method. A $p$ value of $\leq 0.05$ was considered 
significant. Statistical analyses were performed using SigmaStat (version 2.03, SPSS Inc., Chicago, IL) and SPSS 6.1J (SPSS Inc., Chicago, IL). 


\section{RESULTS}

\section{Detection of H.pylori}

Anti-H.pylori antibody was detected in 45 of 93 (48\%) patients. The median serum anti-H.pylori and HCV RNA levels were 1.7 EV (range, 0.4-7.0) and $686 \mathrm{KIU} / \mathrm{ml}$ (range, 6.1-850), respectively. Clinical and virologic features were compared between patients with and without anti-H.pylori in Table 1. A history of blood transfusion was more common in patients with anti-H.pylori than in those without anti-H.pylori (53\% vs. $29 \% ; P=0.022)$. The median platelet count in patients with $H$.pylori was significantly lower than that in those without H.pylori (128 vs. $158 \times 10^{3} / \mu$; $\left.P=0.009\right)$ at the onset of treatment. Additionally, median levels of HCV RNA in serum were significantly lower in patients with anti-H.pylori (495 vs. $760 \mathrm{KIU} / \mathrm{ml} ; P=0.013$ ) (Table 1). Platelet count and fibrosis score were examined for their correlation with levels of anti-H.pylori lgG. The titer of anti-H.pylori was significantly correlated with fibrosis score $(P=0.0083$, $r=0.33)$ though inversely related with platelet count $(P=0.0037, r=-0.34)$ (Figure 1). The rate of HCV response to IFN- $\alpha$ and ribavirin therapy did not differ between patients with and without anti-H.pylori (Table 1).

\section{Effect of H.pylori infection on HCV response to IFN-a and ribavirin therapy}

Of the 93 patients receiving IFN- $\alpha$ and ribavirin therapy, 42 (45\%) were SVRs. There was no significant difference between SVRs and non-SVRs according to sex, history of blood transfusion, or median ALT level at the onset of therapy. SVRs were found more frequently in younger patients $(P=0.032)$ (Table 2). Prior to treatment, median HCV RNA level in the SVR group (460 KIU/ml [range: 6.1-850]) was significantly lower than that in the non-SVR group (718 KIU/ml [range: 140-850], $P=0.022)$. Sustained viral clearance in patients with genotypes $2 \mathrm{a}$ or $2 \mathrm{~b}$ was higher than in those with genotype $1 \mathrm{~b}(P<0.001)$. Sustained HCV response to IFN- $\alpha$ and ribavirin therapy did not differ between patients with and without H.pylori infection. In addition, the titer of anti-H.pylori in serum did not influence response to antiviral therapy (Table 2).

To assess whether H.pylori decreased platelet count during IFN- $\alpha$ and ribavirin therapy, we compared the clinical features of patients who did or did not have a decreased platelet count (less than $70 \times 10^{3} / \mu \mathrm{l}$ ). Complete data at the onset of therapy were available in 69 patients. Of these, six out of 7 patients with cirrhosis had decreased platelet count. Using univariate analysis, anti-H.pylori positivity, HCV viral load, and fibrosis score were associated with a decreased platelet count during combination therapy (data not shown). Table 3 summarizes the multivariate analysis 
of factors possibly influencing the decrease of platelet count during therapy. Of these, presence of H.pylori (odds ratio, 8.61; 95\% confidence interval, 1.59-46.70), and fibrosis score (odds ratio, $30.13 ; 95 \%$ confidence interval, $5.44-166.78$ ) were found to be associated with a decreased platelet count. 


\section{DISCUSSION}

In this study, we found that approximately $50 \%$ of Japanese patients with chronic hepatitis $\mathrm{C}$ were coinfected with H.pylori. This anti-H.pylori seroprevalence is similar to our recent report on healthy individuals in Japan [10]. Although the urea breath test is more specific for an active H.pylori detection, the treatment arm of this study was designed to measure HCV response to IFN- $\alpha$ and ribavirin therapy. Further study using the urea breath test is needed to clarify the exact frequency of H.pylori in chronic patients.

Concerning disease severity, it has been reported that dual infection with $\mathrm{HCV}$ and either hepatitis A virus or hepatitis B virus was associated with more severe and rapidly progressive liver disease [22-24]. However, no evidence was found to suggest that H.pylori increases the severity of chronic hepatitis $C$, since clinical and biochemical evaluations, notably ALT levels, did not differ greatly between patients with HCV infection alone and those coinfected with HCV and H.pylori. This phenomenon comparable to our prior reports on single and coinfection of HCV and hepatitis $G$ and SEN viruses [25-29].

Several reports have demonstrated viral interference between hepatitis $B$ virus and $\mathrm{HCV}[23,30,31]$, and that increasing the replication of one agent can diminish replication of the other. Although there is no evidence of interference between HCV and this bacterium in literature, the HCV RNA titer in patients with HCV and H.pylori coinfection was significantly lower than in patients with HCV infection alone $(P=0.013)$, suggesting that $H$.pylori infection might interfere with $\mathrm{HCV}$ replication. At present, we can only describe the observation of a possibility of viral-bacterium interference and cannot provide a sound scientific basis for its occurrence. Additional studies, for instance HCV replicon system analysis in vitro, would be required to validate this result. While HCV genotype and pre-treatment HCV RNA level were seen to be significantly associated with HCV treatment response in this and prior studies $[32,33]$, there was no significant difference in the sustained HCV treatment response between those who had HCV infection alone and those with $\mathrm{HCV}$ and H.pylori coinfection.

Over the past few years, Helicobacter species have been found to be present in the liver of HCV negative patients, and have been associated with hepatocellular carcinoma (HCC) development in the non-cirrhotic liver [14, 34, 35]. Rocha et al. [16] have recently reported that virtually all patients with HCC are Helicobacter species 
positive in their $\mathrm{HCC}$, and $61-68 \%$ of those with cirrhosis are Helicobacter positive in liver tissue, compared with $4.5 \%$ and $3.2 \%$ of hepatitis patients and controls, respectively. This suggests that the presence of Helicobacter species DNA sequences in the liver may be a co-risk factor in the progression of chronic HCV liver disease. In this study, we demonstrated a strong correlation between the titer of anti-H.pylori and the degree of fibrosis $(P=0.0083 ; r=0.33)$. However, since no patients with HCC were enrolled, we were unable to assess whether the level or positivity of anti-H.pylori was associated with the development of HCC. Since there are no reports that clarify the clinical significance of anti-H.pylori level in patients with liver disease, this significant finding should be expanded in larger populations that contain patients with chronic hepatitis and cirrhosis.

Recently, H.pylori has been suspected to be involved in various autoimmune disorders, including idiopathic thrombocytopenia [36, 37]. Several studies have also reported that the eradication of $H$.pylori is often accompanied by a significant increase in platelet count in patients with idiopathic thrombocytopenia [37, 38]. Although this clinical observation suggests the involvement of H.pylori, little is known about the pathogenesis of H.pylori-associated idiopathic thrombocytopenia. We found that serum platelet count was significantly lower in patients with HCV/H.pylori coinfection in this study as well, and observed an inverse relation between anti-H.pylori titer and platelet count $(P=0.0037)$. Thrombocytopenia is a major hematologic disorder commonly observed in patients with liver cirrhosis. Splenic sequestration of platelets, impaired platelet production from insufficient thrombopoietin secretion, and anti-GPIIb-IIIa autoantibody-mediated platelet destruction have been proposed to be associated with thrombocytopenia in patients with cirrhosis [39-41]. Our results raise the possibility that H.pylori seropositivity might contribute to thrombocytopenia in patients with HCV infection. It is possible, however, that the low platelet counts might have been an indirect consequence of an autoimmune reaction in patients with HCV infection, and may not necessarily indicate the presence of the Helicobacter species in the liver. Using multivariate analysis (Table 4), fibrosis score and the presence of H.pylori were significantly associated with a decrease in platelet count during IFN and ribavirin therapy. Hence, it might be useful to eradicate H.pylori prior to therapy, which would presumably increase platelet count and decrease the rate of reduction or cessation of IFN. Since the treatment arm of the study was initially designed to measure HCV response only, eradication of $H$.pylori had not been performed. 
Eradication of H.pylori in patients with chronic hepatitis C prior to IFN and ribavirin therapy is currently being planned in a forthcoming study.

In conclusion, coexistent H.pylori infection does not influence the clinical course of hepatitis $\mathrm{C}$, but might interfere with $\mathrm{HCV}$ replication. The presence of H.pylori is associated with decreased of platelet count during IFN- $\alpha$ and ribavirin therapy, indicating that pre-emptive eradication of H.pylori may facilitate completion of treatment and an increase of sustained viral response. 


\section{ACKNOWLEDGEMENTS}

Nagano Interferon Treatment Research Group is consisted of following members; Drs. Naoki Tanaka, Noriko Misawa, Koji Orii, (Internal Medicine, Shinshu University School of Medicine, Matsumoto), Dr. Yasuharu Imai (Nagano Municipal Hospital, Nagano), Dr. Shuichi Wada (Nagano Red-cross Hspital, Nagano), Dr. Yoshiyuki Nakatsuji (National Nagano Hospital, Ueda), Dr. Chiharu Miyabayashi (Chikuma Central Hospital、 Chikuma), Dr. Haruhiko Imai (Yodakubo Hospital, Nagato-machi), Dr. Masato Takamatsu (Saku Central Hospital, Usuda), Drs. Takeshi Sodeyama, Masakazu Kobayashi (National Chushin Matsumoto Hospital, Matsumoto), Drs. Kiyoshi Furuta, Yukio Gibo (National Matsumoto Hospital, Matsumoto), Dr. Seiichi Usuda ( Aizawa Hospital, Matsumoto), Dr. Akihiko Urushibara (Tatsuno Hospital, Tatsuno-machi), Dr. Hidetoshi Yoda (NTT Nagano Hospital, Nagano), Dr. Toshihisa Tsukadaira (Kenwakai Hospital, lida), Dr. Yuriko Koike (Kawanakajima clinic, Nagano), Dr. Kaoru Arai (Hata Hospital, Hata), Dr. Wataru Okiyama (Suwa Red-cross Hospital, Suwa), Dr. Atsushi Maruyama (Showainan Hospital, Komagane), Dr. Takahiro Yamaura (lida Municipal Hospital, lida), Dr. Akihiro lijima (Kiso Prefecture Hospital). We thank Toyo Amaki and Asami Yamazaki for their technical assistance, and Trevor Ralph for his editorial assistance. 


\section{REFERENCES}

1. Alter HJ, Purcell RH, Shih JW, et al. Detection of antibody to hepatitis $\mathrm{C}$ virus in prospectively followed transfusion recipients with acute and chronic non-A, non-B hepatitis. N Engl J Med 1989;321:1494-500

2. Kiyosawa K, Sodeyama T, Tanaka E, et al. Interrelationship of blood transfusion, non-A, non-B hepatitis and hepatocellular carcinoma: analysis by detection of antibody to hepatitis C virus. Hepatology 1990;12:671-5

3. Alter HJ, Seeff LB. Recovery, persistence, and sequelae in hepatitis C virus infection: a perspective on long-term outcome. Semin Liver Dis 2000;20:17-35

4. Kiyosawa K, Umemura T, Ichijo T, et al. Hepatocellular carcinoma: recent trends in Japan. Gastroenterology 2004;127:S17-26

5. McHutchison JG, Gordon SC, Schiff ER, et al. Interferon alfa-2b alone or in combination with ribavirin as initial treatment for chronic hepatitis $\mathrm{C}$. Hepatitis Interventional Therapy Group. N Engl J Med 1998;339:1485-92

6. Poynard T, Marcellin P, Lee SS, et al. Randomised trial of interferon alpha2b plus ribavirin for 48 weeks or for 24 weeks versus interferon alpha2b plus placebo for 48 weeks for treatment of chronic infection with hepatitis $C$ virus. International Hepatitis Interventional Therapy Group (IHIT). Lancet 1998;352:1426-32

7. Manns MP, McHutchison JG, Gordon SC, et al. Peginterferon alfa-2b plus ribavirin compared with interferon alfa-2b plus ribavirin for initial treatment of chronic hepatitis C: a randomised trial. Lancet 2001;358:958-65

8. Fried MW, Shiffman ML, Reddy KR, et al. Peginterferon alfa-2a plus ribavirin for chronic hepatitis C virus infection. N Engl J Med 2002;347:975-82

9. Chen SY, Liu TY, Chen MJ, Lin JT, Sheu JC and Chen CJ. Seroprevalences of hepatitis $\mathrm{B}$ and $\mathrm{C}$ viruses and Helicobacter pylori infection in a small, isolated population at high risk of gastric and liver cancer. Int J Cancer 1997;71:776-9 10. Fujisawa T, Kumagai T, Akamatsu T, Kiyosawa K and Matsunaga Y. Changes in seroepidemiological pattern of Helicobacter pylori and hepatitis A virus over the last 20 years in Japan. Am J Gastroenterol 1999;94:2094-9

11. Pellicano R, Leone N, Berrutti M, et al. Helicobacter pylori seroprevalence in hepatitis C virus positive patients with cirrhosis. J Hepatol 2000;33:648-50

12. Zucca E, Roggero E, Maggi-Solca N, et al. Prevalence of Helicobacter pylori and hepatitis $\mathrm{C}$ virus infections among non-Hodgkin's lymphoma patients in Southern Switzerland. Haematologica 2000;85:147-53 
13. Durazzo M, Pellicano R, Premoli A, et al. Helicobacter pylori seroprevalence in patients with autoimmune hepatitis. Dig Dis Sci 2002;47:380-3

14. Dore MP, Realdi G, Mura D, Graham DY and Sepulveda AR. Helicobacter infection in patients with HCV-related chronic hepatitis, cirrhosis, and hepatocellular carcinoma. Dig Dis Sci 2002;47:1638-43

15. Malaty HM, Tanaka E, Kumagai T, et al. Seroepidemiology of Helicobacter pylori and hepatitis A virus and the mode of transmission of infection: a 9-year cohort study in rural Japan. Clin Infect Dis 2003;37:1067-72

16. Rocha M, Avenaud P, Menard A, et al. Association of Helicobacter species with hepatitis C cirrhosis with or without hepatocellular carcinoma. Gut 2005;54:396-401 17. Boomkens SY, Rave S, Pot RG, et al. The role of Helicobacter spp. in the pathogenesis of primary biliary cirrhosis and primary sclerosing cholangitis. FEMS Immunol Med Microbiol 2005;44:221-5

18. Knodell RG, Ishak KG, Black WC, et al. Formulation and application of a numerical scoring system for assessing histological activity in asymptomatic chronic active hepatitis. Hepatology 1981;1:431-5

19. Scheuer PJ. Classification of chronic viral hepatitis: a need for reassessment. J Hepatol 1991;13:372-4

20. Marchildon PA, Sugiyama T, Fukuda Y, et al. Evaluation of the effects of strain-specific antigen variation on the accuracy of serologic diagnosis of Helicobacter pylori infection. J Clin Microbiol 2003;41:1480-5

21. Umemura T, Wang RY, Schechterly C, Shih JW, Kiyosawa K and Alter HJ. Quantitative analysis of anti-hepatitis $C$ virus antibody-secreting $B$ cells in patients with chronic hepatitis C. Hepatology 2006;43:91-99

22. Cacciola I, Pollicino T, Squadrito G, Cerenzia G, Orlando ME and Raimondo G. Occult hepatitis $\mathrm{B}$ virus infection in patients with chronic hepatitis $\mathrm{C}$ liver disease. $\mathrm{N}$ Engl J Med 1999;341:22-6

23. Pontisso P, Ruvoletto MG, Fattovich G, et al. Clinical and virological profiles in patients with multiple hepatitis virus infections. Gastroenterology 1993;105:1529-33 24. Vento S, Garofano T, Renzini C, et al. Fulminant hepatitis associated with hepatitis $A$ virus superinfection in patients with chronic hepatitis $C$. N Engl J Med 1998;338:286-90

25. Tanaka E, Alter HJ, Nakatsuji Y, et al. Effect of hepatitis $G$ virus infection on chronic hepatitis C. Ann Intern Med 1996;125:740-3 
26. Umemura T, Yeo AE, Sottini A, et al. SEN virus infection and its relationship to transfusion-associated hepatitis. Hepatology 2001;33:1303-11

27. Umemura T, Alter HJ, Tanaka E, et al. Association between SEN virus infection and hepatitis C in Japan. J Infect Dis 2001;184:1246-51

28. Umemura T, Alter HJ, Tanaka E, et al. SEN virus: response to interferon alfa and influence on the severity and treatment response of coexistent hepatitis $\mathrm{C}$. Hepatology 2002;35:953-9

29. Umemura T, Tanaka E, Ostapowicz G, et al. Investigation of SEN virus infection in patients with cryptogenic acute liver failure, hepatitis-associated aplastic anemia, or acute and chronic non-A-E hepatitis. J Infect Dis 2003;188:1545-52

30. Sagnelli E, Coppola N, Scolastico C, et al. Virologic and clinical expressions of reciprocal inhibitory effect of hepatitis $B, C$, and delta viruses in patients with chronic hepatitis. Hepatology 2000;32:1106-10

31. Jardi R, Rodriguez F, Buti M, et al. Role of hepatitis $B, C$, and D viruses in dual and triple infection: influence of viral genotypes and hepatitis B precore and basal core promoter mutations on viral replicative interference. Hepatology 2001;34:404-10 32. Tanaka E, Ohue C, Aoyagi K, et al. Evaluation of a new enzyme immunoassay for hepatitis $\mathrm{C}$ virus ( $\mathrm{HCV}$ ) core antigen with clinical sensitivity approximating that of genomic amplification of HCV RNA. Hepatology 2000;32:388-93

33. Di Bisceglie AM, Hoofnagle JH. Optimal therapy of hepatitis C. Hepatology 2002;36:S121-7

34. Avenaud P, Marais A, Monteiro L, et al. Detection of Helicobacter species in the liver of patients with and without primary liver carcinoma. Cancer 2000;89:1431-9 35. Nilsson HO, Mulchandani R, Tranberg KG, Stenram U and Wadstrom T. Helicobacter species identified in liver from patients with cholangiocarcinoma and hepatocellular carcinoma. Gastroenterology 2001;120:323-4

36. Franchini M, Veneri D. Helicobacter pylori infection and immune thrombocytopenic purpura: an update. Helicobacter 2004;9:342-6

37. Michel M, Cooper N, Jean C, Frissora C and Bussel JB. Does Helicobater pylori initiate or perpetuate immune thrombocytopenic purpura? Blood 2004;103:890-6 38. Stasi R, Rossi Z, Stipa E, Amadori S, Newland AC and Provan D. Helicobacter pylori eradication in the management of patients with idiopathic thrombocytopenic purpura. Am J Med 2005;118:414-9

39. Aster RH. Pooling of platelets in the spleen: role in the pathogenesis of 
"hypersplenic" thrombocytopenia. J Clin Invest 1966;45:645-57

40. Shimodaira S, Ishida F, Ichikawa N, et al. Serum thrombopoietin (c-Mpl ligand) levels in patients with liver cirrhosis. Thromb Haemost 1996;76:545-8

41. Kajihara M, Kato S, Okazaki Y, et al. A role of autoantibody-mediated platelet destruction in thrombocytopenia in patients with cirrhosis. Hepatology 2003;37:1267-76 
Table 1. Clinical features of Helicobacter pylori (H.pylori) positive and H.pylori negative patients with chronic hepatitis C

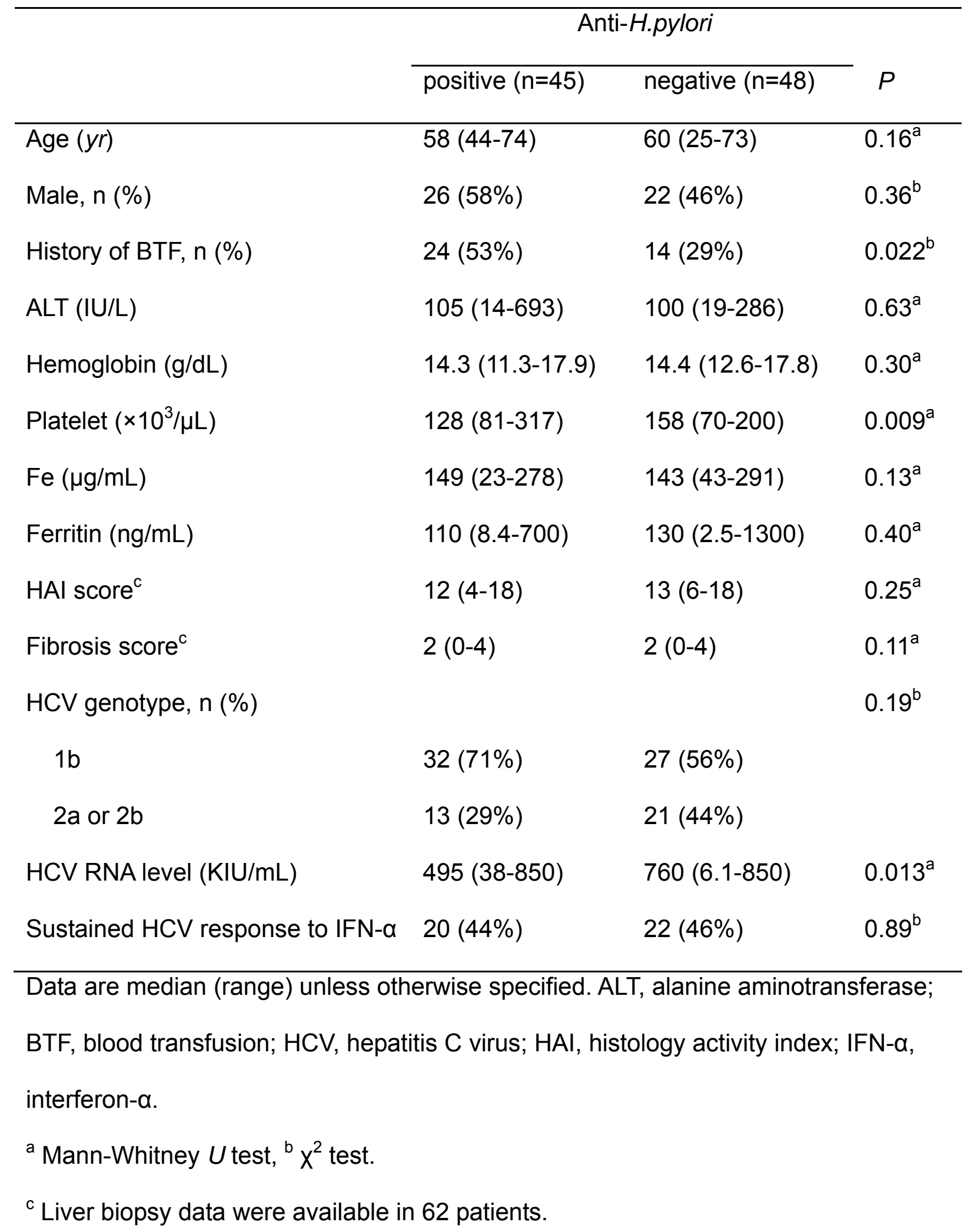


Table 2. Hepatitis $\mathrm{C}$ virus (HCV) response to interferon- $\alpha$ and ribavirin therapy in relation to HCV viral load, genotype and Helicobacter pylori (H.pylori) status

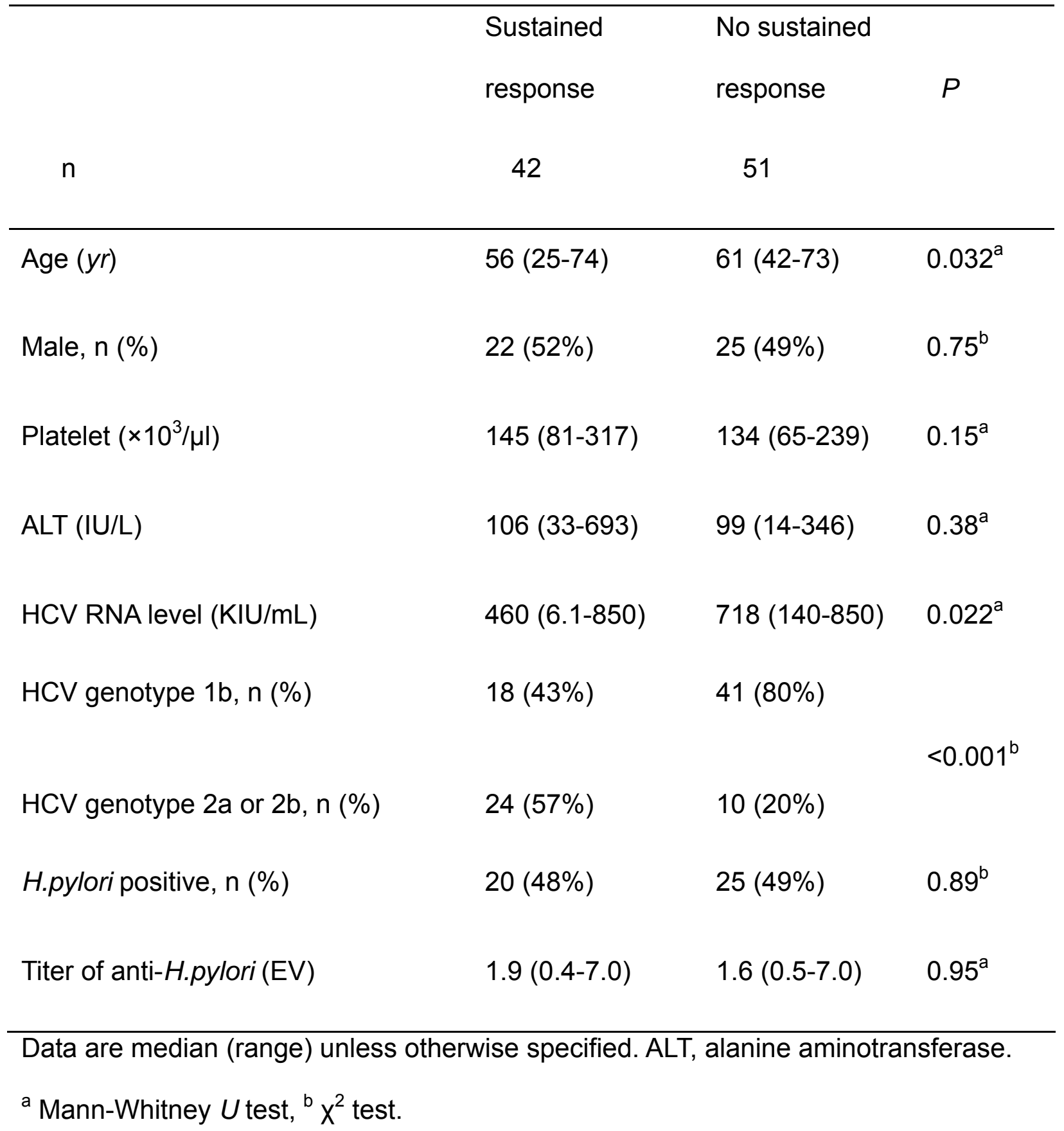


Table 3. Multivariate analysis of factors associated with thrombocytopenia during interferon- $\alpha$ and ribavirin therapy in 69 patients with chronic hepatitis $C$ Factor $\mathrm{n} \quad$ Odds ratio $(95 \% \mathrm{Cl})$ $P$

Age $(y r)$

$\begin{array}{lllll}65- & 28 & 1.00 & & \\ 55-64 & 26 & 0.11 & (0.01-0.83) & 0.033 \\ -54 & 15 & 0.66 & (0.08-5.59) & 0.70\end{array}$

ALT (IU/L)

$\begin{array}{lllll}<110 & 42 & 1.00 & & \\ \geq 110 & 27 & 4.04 & (0.86-18.91) & 0.077\end{array}$

Helicobacter pylori

$\begin{array}{lllll}\text { negative } & 37 & 1.00 & & \\ \text { positive } & 32 & 8.61 & (1.59-46.70) & 0.013\end{array}$

Fibrosis score

$\begin{array}{lcrll}0-2 & 19 & 1.00 & & \\ 3 & 25 & 4.84 & (0.65-36.13) & 0.12 \\ 4 & 7 & 30.13 & (5.44-166.78) & 0.0053 \\ \text { unknown } & 18 & 0.92 & (0.10-8.46) & 0.94\end{array}$

$\mathrm{Cl}$, confidence interval; ALT, alanine aminotransferase. 
Figure Legend

Figure 1. Influence of anti-Helicobacter pylori (H.pylori) titer on clinical characteristics in patients with chronic hepatitis C

The titer of anti-H.pylori was significantly correlated with fibrosis score $(A ; r=0.33$, $P=0.0083)$ and inversely correlated with platelet count $(B ; r=-0.34, P=0.0037)$ 
Figure 1A

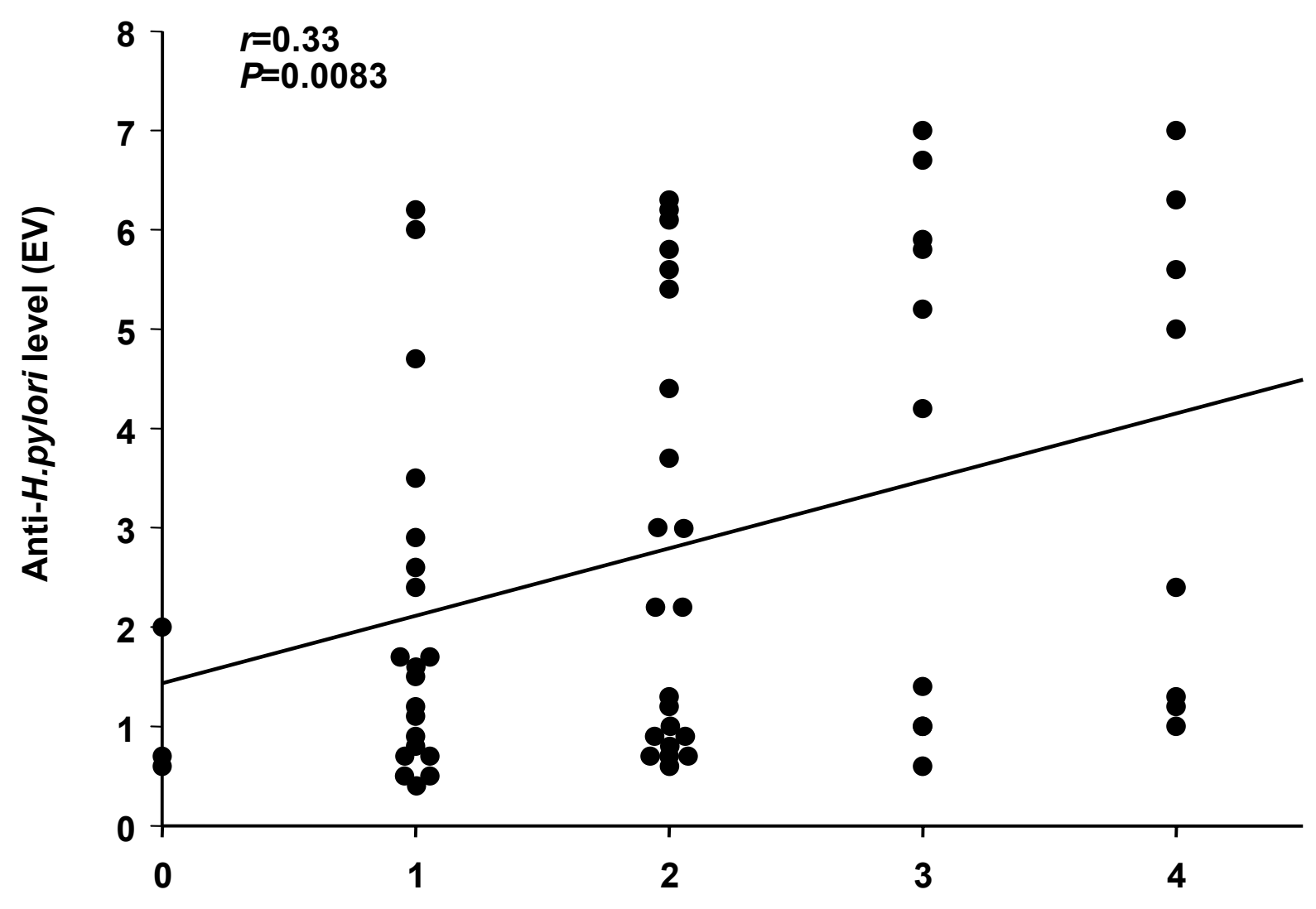

Fibrosis score 
Figure 1B

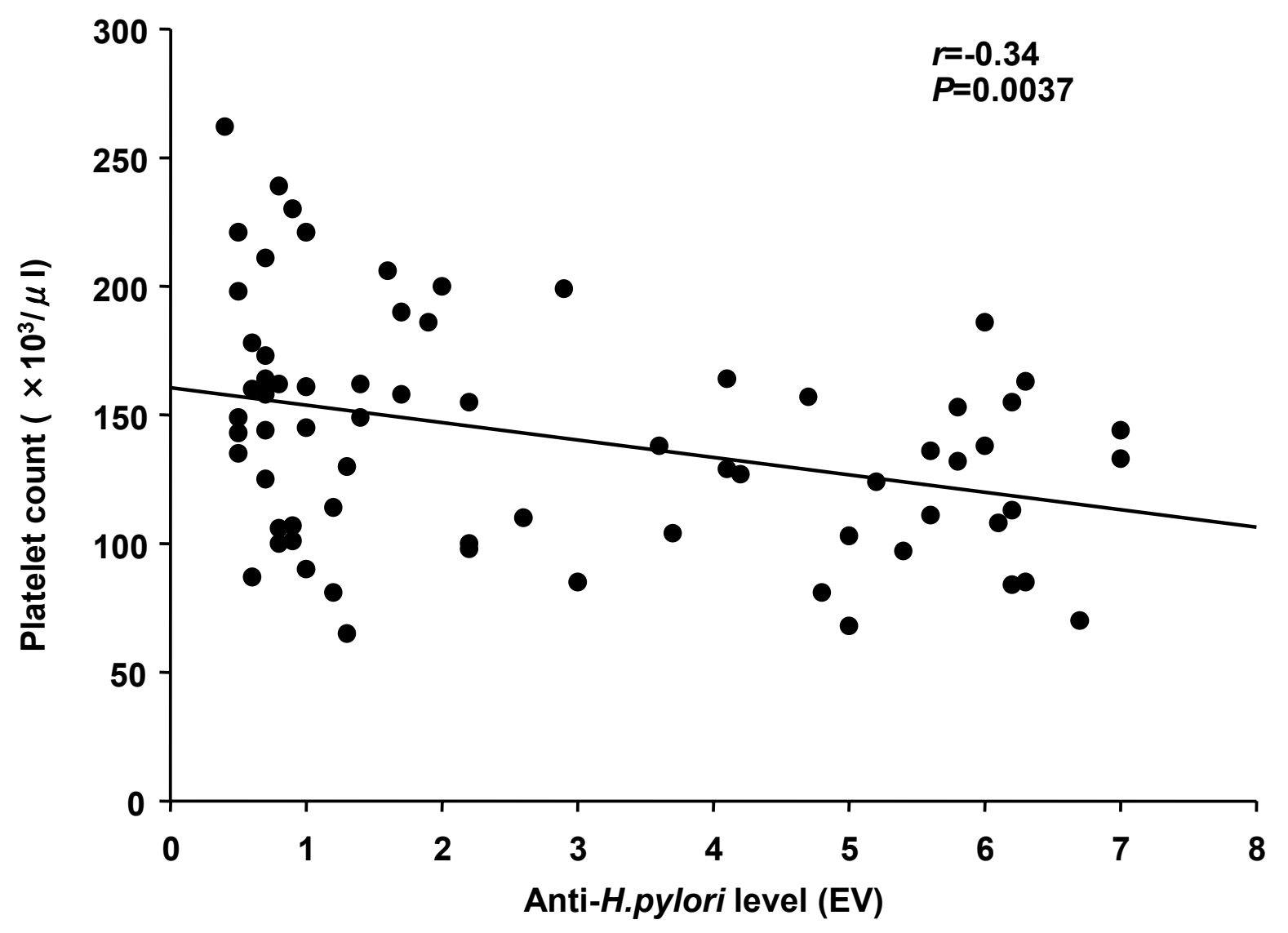

